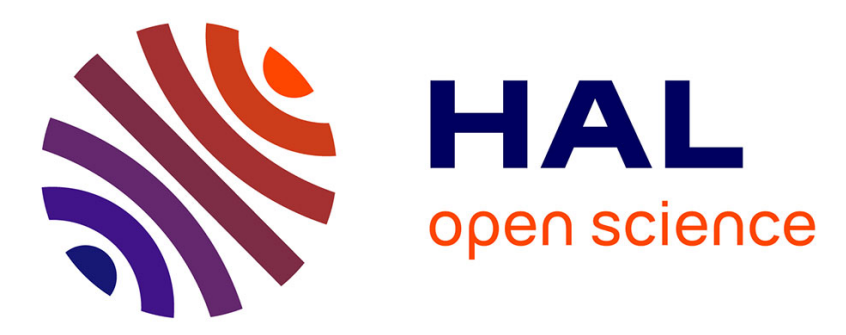

\title{
Improvement of jet flow simulations using ZDES mode 3 and silent turbulence generation
}

\author{
Fabien Gand, Maxime Huet
}

\section{To cite this version:}

Fabien Gand, Maxime Huet. Improvement of jet flow simulations using ZDES mode 3 and silent turbulence generation. 25th AIAA/CEAS Aeroacoustics Conference 2019, May 2019, DELFT, Netherlands. 10.2514/6.2019-2687 . hal-02333591

\section{HAL Id: hal-02333591 \\ https://hal.science/hal-02333591}

Submitted on 25 Oct 2019

HAL is a multi-disciplinary open access archive for the deposit and dissemination of scientific research documents, whether they are published or not. The documents may come from teaching and research institutions in France or abroad, or from public or private research centers.
L'archive ouverte pluridisciplinaire HAL, est destinée au dépôt et à la diffusion de documents scientifiques de niveau recherche, publiés ou non, émanant des établissements d'enseignement et de recherche français ou étrangers, des laboratoires publics ou privés. 


\title{
Improvement of jet flow simulations using ZDES mode 3 and silent turbulence generation
}

\author{
F. Gand ${ }^{1}$ and M. Huet ${ }^{2}$ \\ $D A A A$, ONERA, Université Paris Saclay
}

\begin{abstract}
This paper presents hybrid RANS/LES simulations of an isothermal round jet at Mach number $M=0.9$ and Reynolds number based on the nozzle exit diameter $\operatorname{Re}=10^{6}$. The study is focused on the effect of the RANS to LES transition in the early stages of the jet mixing layer on the properties of the spatial organization of the fluctuating field. In order to capture the salient features of the nozzle internal boundary layer, which is essential to reproduce the jet flow development and acoustics, the Zonal Detached Eddy Simulation mode 3 (i.e. WMLES mode of ZDES) is used to resolve the external part of the boundary layer in LES. The advantage of using this methodology are demonstrated by comparing the results of the simulation with experimental data and another simulation involving ZDES mode 2 (i.e. automatic mode of ZDES) where the whole boundary layer is treated in RANS.

In the present extended abstract, the results of the ZDES mode 2 simulation and preliminary results of the ZDES mode 3 simulation are shown. The final paper will provide an extensive cross-comparison between experimental data, ZDES mode 2 and ZDES mode 3 simulations. The issue of the turbulence generation inside the nozzle to feed the ZDES mode 3 will also be tackled, with a focus on the acoustic perturbations associated to the turbulence generation method.
\end{abstract}

\section{Nomenclature}

$D=\quad$ Nozzle exit section diameter $(\mathrm{D}=0.05 \mathrm{~m})$

$\mathrm{M} \quad=$ Nozzle exit Mach number $(\mathrm{M}=0.9)$

$\mathrm{U}_{\mathrm{j}} \quad=$ Jet exhaust velocity

\section{Introduction}

To improve both the physical understanding of jet noise generation mechanisms and the design of future aircraft engine nozzles, accurate numerical simulations are required to complete wind-tunnel data. The simulation of jet flows involves two major challenges. On the one hand, turbulence production mechanisms need to be accurately reproduced since they are the cornerstone of the jet flow development and noise generation. This leads to the use of eddy-resolving simulations such as LES [1] and hybrid RANS/LES methods which are less expensive and thus applicable to technical configurations at high Reynolds numbers [2]. On the other hand, numerical schemes have to be accurate enough to propagate acoustic waves over large distances with low dissipation and dispersion.

This paper is devoted to the first issue at stake, turbulence modelling. In particular, it has been stressed in a number of publications that the resolution of the nozzle boundary layer - in terms of integral quantities and resolved Reynolds stresses - is required to reach the level of agreement with experimental data needed by aircraft makers design teams. Therefore, two approaches are used in the present study. The first one corresponds to a standard RANS/LES simulation with ZDES mode 2 [3], where the boundary layer is treated in RANS. Although this rather standard method has proven to be efficient for massively separated flows on complex geometries [2], it fails to capture accurately the jet acoustics due to the RANS/LES transition that occurs near the nozzle exit [4] [5], where the model switches automatically from RANS to LES. To overcome this issue, the second approach investigated in

\footnotetext{
1 Research scientist, Aerodynamics, aeroelasticity and acoustics department, F-92190 Meudon - France, fabien.gand@onera.fr

${ }^{2}$ Research scientist, Aerodynamics, aeroelasticity and acoustics department, F-92322 Châtillon - France
} 
this paper relies on the use of ZDES mode 3 in the nozzle in order to resolve in LES mode the external part of the boundary layer [6]. The mode 3 of ZDES is indeed the WMLES operating mode of ZDES [7].

The paper is organized as follows. First, the jet flow configuration investigated is described in section III. Then the computational framework is presented in section IV, including the turbulence modelling approach, numerical parameters and grids used. The jet near-field is investigated in section V. Finally, the far-field acoustics predicted by the simulations is investigated, both in terms of directivity and spectral content.

\section{Jet flow configuration}

The configuration investigated in this paper is an isothermal subsonic jet issued from a round nozzle of exit diameter $\mathrm{D}=50 \mathrm{~mm}$. The experiments were performed at the Bruit et Vent jet-noise facility of the Institut Pprime, Poitiers, France. Table 1 summarizes the flow conditions, and details about the experiments and measurements techniques can be found in [7] and [8].

Of interest, the experimental data as well as reference numerical results from [8] have been made available online, which makes this database ideal for the evaluation of numerical simulations.

\begin{tabular}{|l|c|r|}
\hline \multicolumn{3}{|c|}{ External flow } \\
\hline Pressure & $\mathrm{p}_{\infty}$ & $100000 \mathrm{~Pa}$ \\
\hline Temperature & $\mathrm{T}_{\infty}$ & $293 \mathrm{~K}$ \\
\hline Mach number & $\mathrm{M}_{\infty}$ & 0. \\
\hline \multicolumn{3}{|c|}{ Jet } \\
\hline Nozzle exit diameter & $\mathrm{D}$ & $0.05 \mathrm{~m}$ \\
\hline Total pressure & $\mathrm{pt}$ & $170000 \mathrm{~Pa}$ \\
\hline Total temperature & $\mathrm{Tt}$ & $337 \mathrm{~K}$ \\
\hline Mach number & $\mathrm{Mj}$ & 0.9 \\
\hline Reynolds number $(\mathrm{D})$ & $\mathrm{Re}$ & $1.010^{6}$ \\
\hline \multicolumn{3}{|c|}{ Nozzle exit boundary layer } \\
\hline \multicolumn{3}{|c|}{$\delta$} \\
\hline
\end{tabular}

Table 1. Aerodynamic conditions of the Pprime jet experiments

\section{Computational framework}

\section{A. Turbulence modelling approach: Zonal Detached Eddy Simulation (ZDES)}

In the final paper, the formulation of ZDES mode 2 and mode 3 will be recalled. Emphasis will also be put on the approach used to initiate turbulent fluctuations in the boundary layer for the ZDES mode 3 simulation, which is a key issue for aeroacoustic simulations. A recent approach published in Ref [9] is used in the present study. Its setup will be detailed.

\section{B. Numerical setup}

The simulations were performed with the elsA software [10]. Tthe time integration is performed using an implicit LU-SSOR algorithm and a second-order accurate backward Euler Gear scheme. The number of subiterations is adjusted to reach a convergence of one order of magnitude of the inner iteration residuals to achieve second-order time accuracy. For the present simulations, 8 Newton sub-iterations were used.

For the spatial integration, the diffusive fluxes are discretized using a second-order-accurate centered scheme. The convective terms are treated with a hybrid centered/upwind second-order-accurate modified AUSM+P scheme [11] using a third order MUSCL extrapolation. This version of the AUSM scheme involves a "wiggle" sensor to minimize numerical viscosity by applying some upwinding only in areas where the solution displays numerical oscillations, while the scheme is actually centered everywhere else.

In order to compute the far field noise, far-field pressure time signals are reconstructed from the unsteady aerodynamic flow fields stored on surfaces surrounding the jet in the near field, using the Ffowcs-Williams and 
Hawkings integral formulation [12]. Three surfaces with different radial positions are used to ensure the stability of the noise radiation process (i.e. to check the independence of the results with the location of the surface). Those surfaces are closed at both extremities and radiation is achieved using a formulation with additional flux terms proposed by Rahier et al. [13]. This methodology differs from the one traditionally used in jet noise radiation problems, where the surfaces are kept open to avoid spurious noise radiation caused by the turbulence crossing the storage area. With the additional flux terms, spurious radiation from turbulence becomes negligible compared to the physically radiated noise. The advantages of this new formulation are manifold [13]. In particular, it improves the stability of the noise computed from the different surfaces, especially in the low frequency part of the spectra. Three different positions of the downstream closing disk are considered in the simulation to ensure radiated pressure signals do not vary with the axial extent of the storage surfaces.

For the statistical analysis of the results, aerodynamic simulations were time-averaged over $\mathrm{T}=0.05 \mathrm{~s}=300 \mathrm{D} / \mathrm{U}_{\mathrm{j}}$ after an initial transient stage of $0.02 \mathrm{~s}=140 \mathrm{D} / \mathrm{U}_{\mathrm{j}}$. The total cost of one simulation was around $50.10^{3} \mathrm{CPU}$ hours. Due to transient parts at the beginning and end of the radiation process, far-field pressure signals are analyzed over a duration of $260 \mathrm{D} / \mathrm{U}_{\mathrm{j}}$.

\section{Computational domain and grids}

Figure 1 illustrates the computational domain size and boundary conditions used. To avoid reflections; the grid is stretched outside the area of interest and the limits of the computational domain are placed far from the jet (40D in the radial direction and $70 \mathrm{D}$ in the streamwise direction).

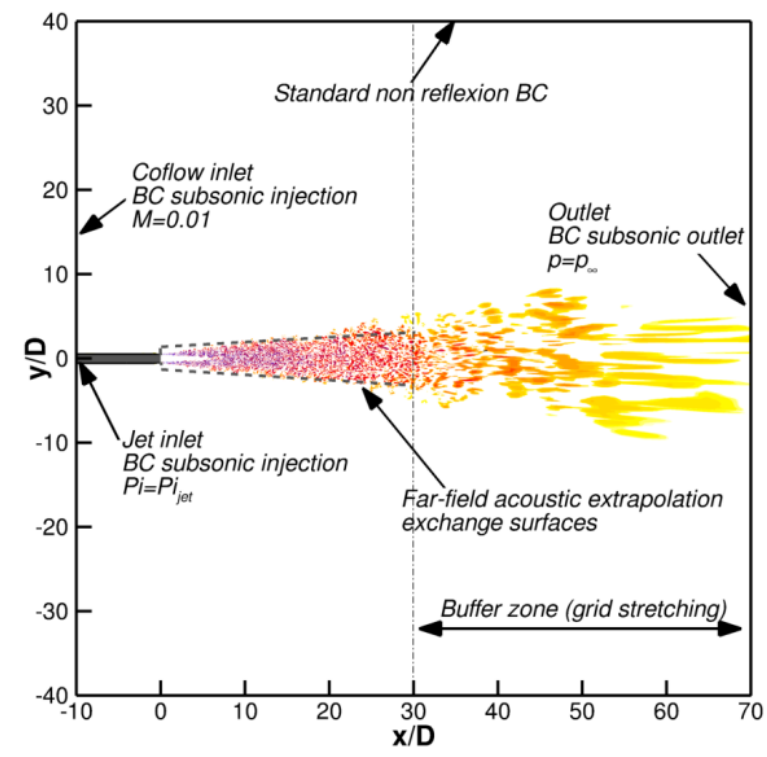

Figure 1. Computational domain

The numerical setup for the ZDES mode 3 simulation involves the zonal definition of the turbulence modelling applied in the nozzle, as depicted in Figure 2. The resolved turbulent content is triggered using the IBC technique following the guidelines suggested in [9]. The tripping dots included in the nozzle with IBC are shown in Figure 3. 


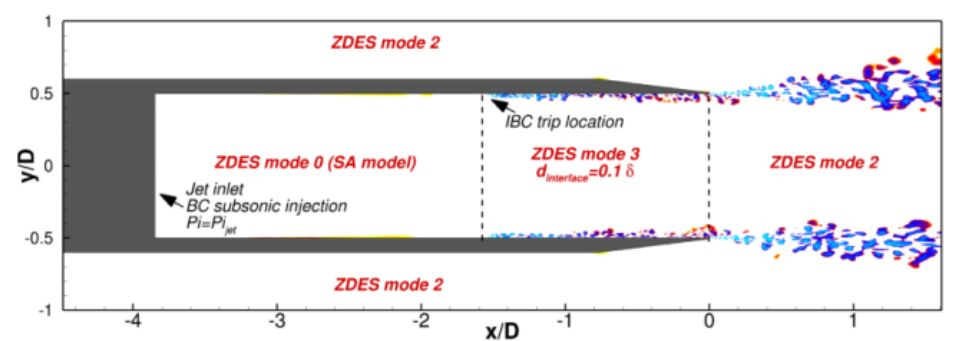

Figure 2. ZDES modes selection for the ZDES mode 3 simulation

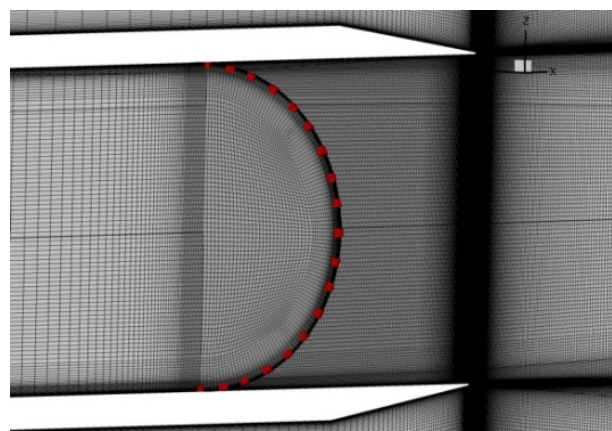

Figure 3. Visualization of the IBC roughness elements inside the nozzle for the ZDES mode 3 simulation

The grid sizes were chosen in accordance with the existing literature guidelines and previous experience of the Authors. As shown in Figure 4, the grid stretching in the area of interest is limited to $2 \%$ to limit the numerical dissipation. In the azimuthal direction, 260 nodes were used. Overall, the grid contains $52.10^{6}$ nodes for the ZDES mode 2 simulation. The grid was refined only locally inside the nozzle in the streamwise direction in order to reach a resolution of $\Delta \mathrm{x}^{+}=200$ as recommended for ZDES mode 3 [6] [7]. Note that the azimuthal resolution has been chosen rather coarse for ZDES mode 3 on purpose $\left(r \Delta \theta^{+}=400\right)$ in order to assess the ZDES mode 3 approach on a grid typically made for the jet flow, with a cost equivalent to the ZDES mode 2 simulation. Indeed, the addition of grid points only in the streamwise direction adds $3.10^{6}$ grid points.
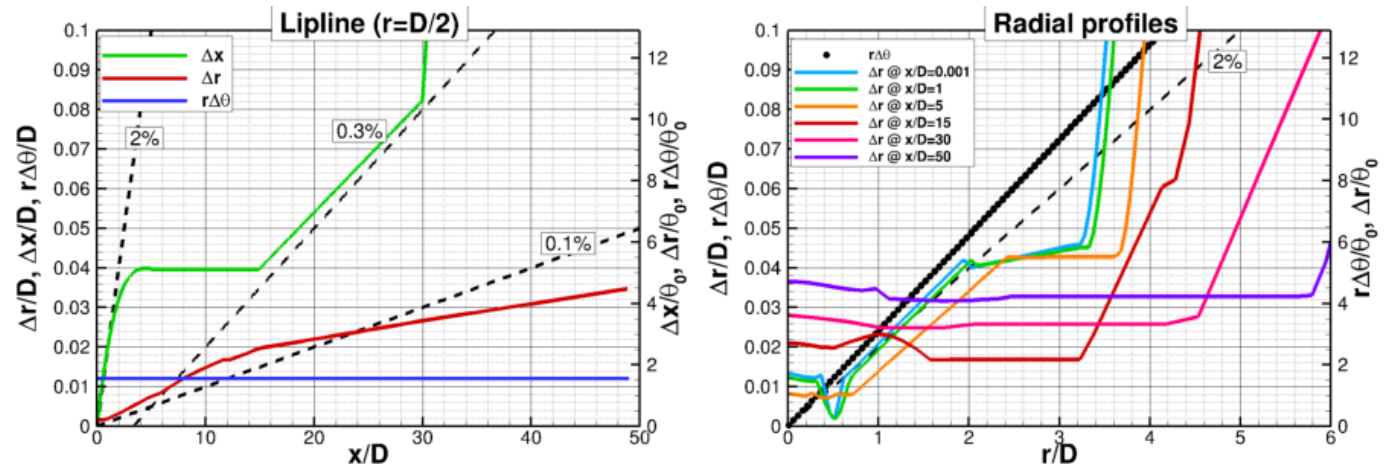

Figure 4. Grid sizes along the lip line and in the jet development area

\section{Near-field results}

In the present extended abstract, only preliminary results are presented and compared with the database. In particular, only instantaneous data are presented for the ZDES mode 3 simulation since it is not completed at the time of the abstract submission.

\section{A. Instantaneous visualizations}

Figure 5, Figure 6 and Figure 7 illustrate the simulations investigated. The turbulent structures resolved in the jet appear fairly similar with both approaches, but Figure 6 clearly shows that the some turbulence is resolved inside the boundary layer in the ZDES mode 3 simulation, conversely to the ZDES mode 2 simulation as expected. 


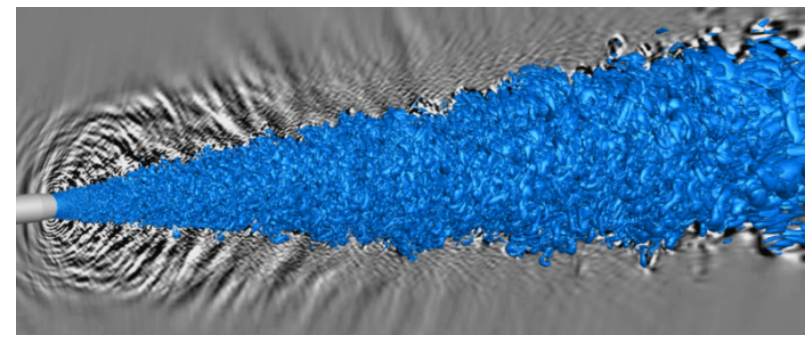

(a) ZDES mode 2

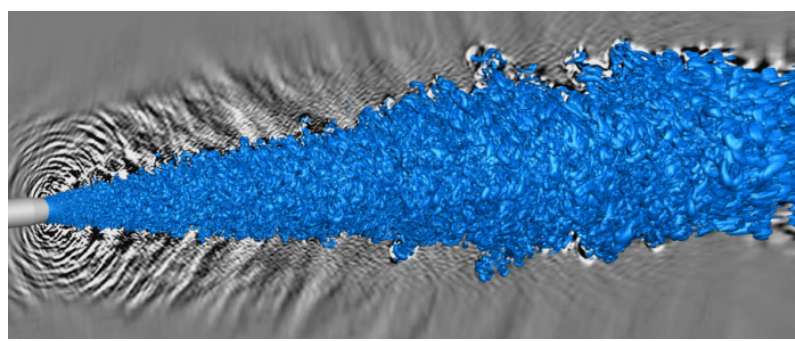

(b) ZDES mode 3

Figure 5. Snapshots of the simulations. Iso- $Q$ criterion and gradient of density

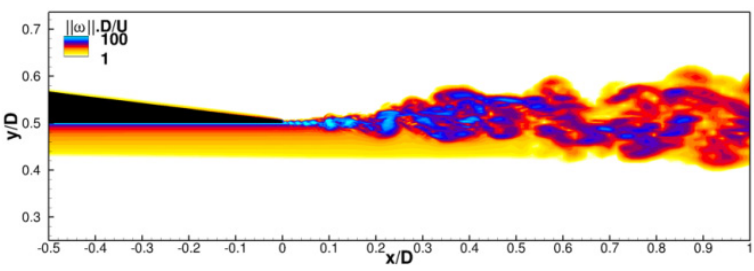

(a) ZDES mode 2

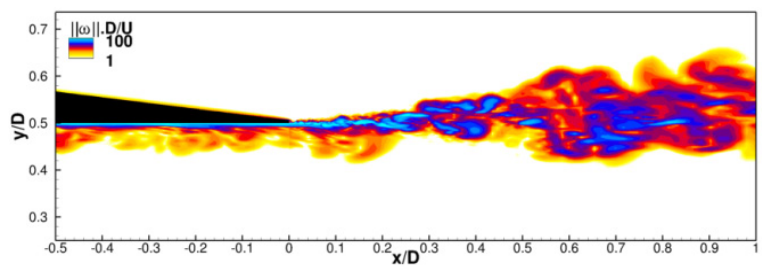

(b) ZDES mode 3

Figure 6. Snapshots of the simulations. Close-up on the nozzle exit, magnitude of vorticity
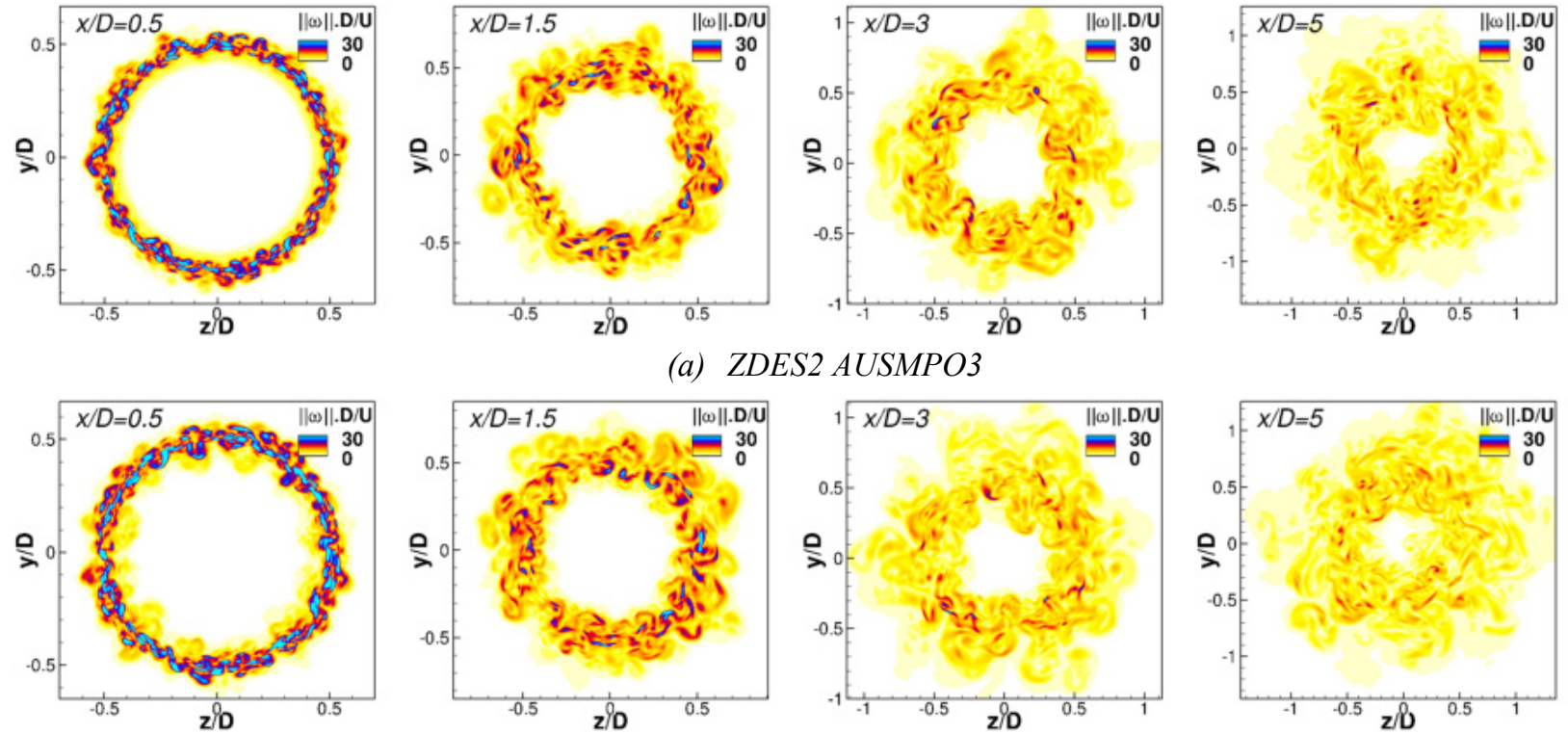

(b) ZDES3 AUSMPO3

Figure 7. Snapshots of the simulations. Cross-jet planes, magnitude of vorticity

\section{B. Nozzle exit boundary layer}

The nozzle exit boundary layer profiles are plotted in Figure 8 and Figure 9. These quantities are of outmost importance for the prediction of the jet flow development and acoustic sources [8] [1]. As expected, the ZDES mode 2 acts in RANS mode in the nozzle and therefore is able to recover the mean velocity profile. However, the velocity fluctuations are not present in the ZDES mode 2 simulation.

In the final paper, emphasis will be put on the boundary layer characteristics obtained with the ZDES mode 3 simulation. 


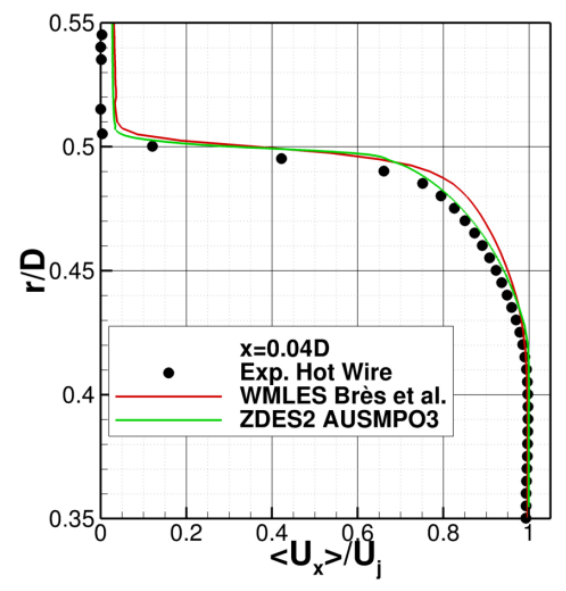

Figure 8. Nozzle exit velocity profiles at $\mathbf{x} / \mathrm{D}=\mathbf{0 . 0 4}$

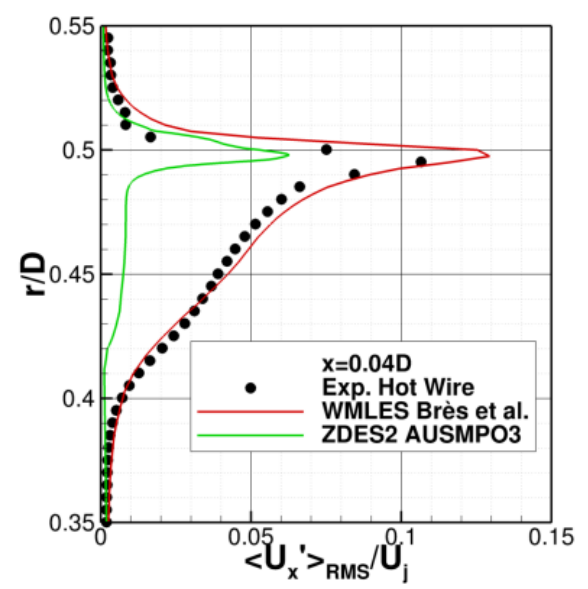

Figure 9. Reynolds stresses profiles at the nozzle exit $(\mathbf{x} / \mathbf{D}=\mathbf{0 . 0 4})$

\section{Jet flow statistics}

The jet flow development predicted by the ZDES mode 2 simulation is in a fair agreement with the experimental data (see Figure 10 and Figure 11). The velocity fluctuations are slightly underestimated both along the lipline and the centerline, which may be due to a somewhat too coarse grid. A refined grid may be used for the final paper to improve these preliminary results, in particular if no improvement is obtained with the ZDES mode 3 simulation. The RANS to LES transition occurs very quickly downstream of the nozzle exit as depicted in Figure 12.

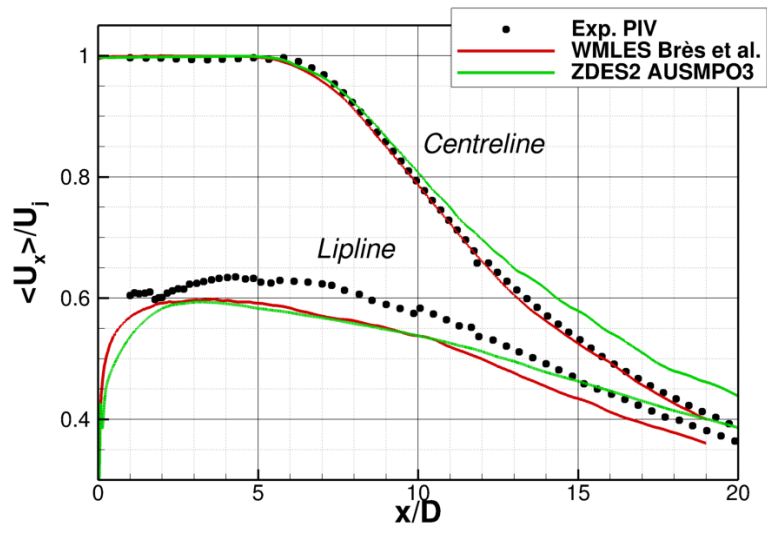

Figure 10. Mean velocity profiles along the centreline and the lipline

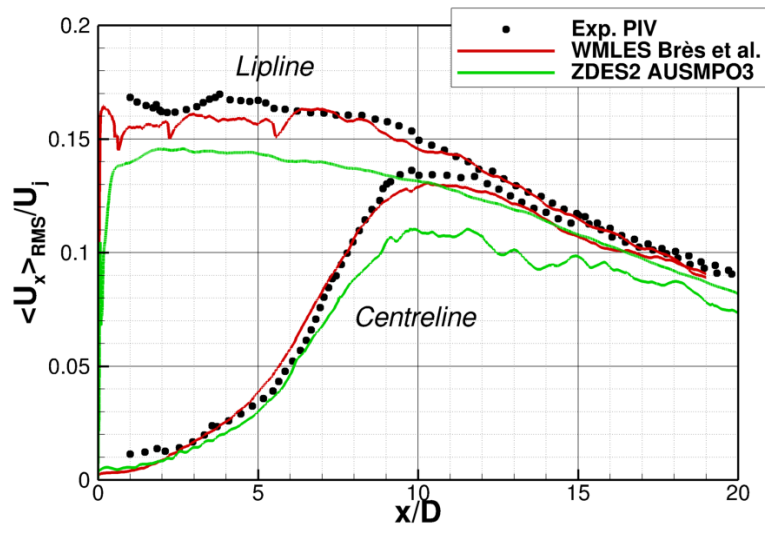

Figure 11. RMS of streamwise velocity fluctuations along the centreline and the lipline 

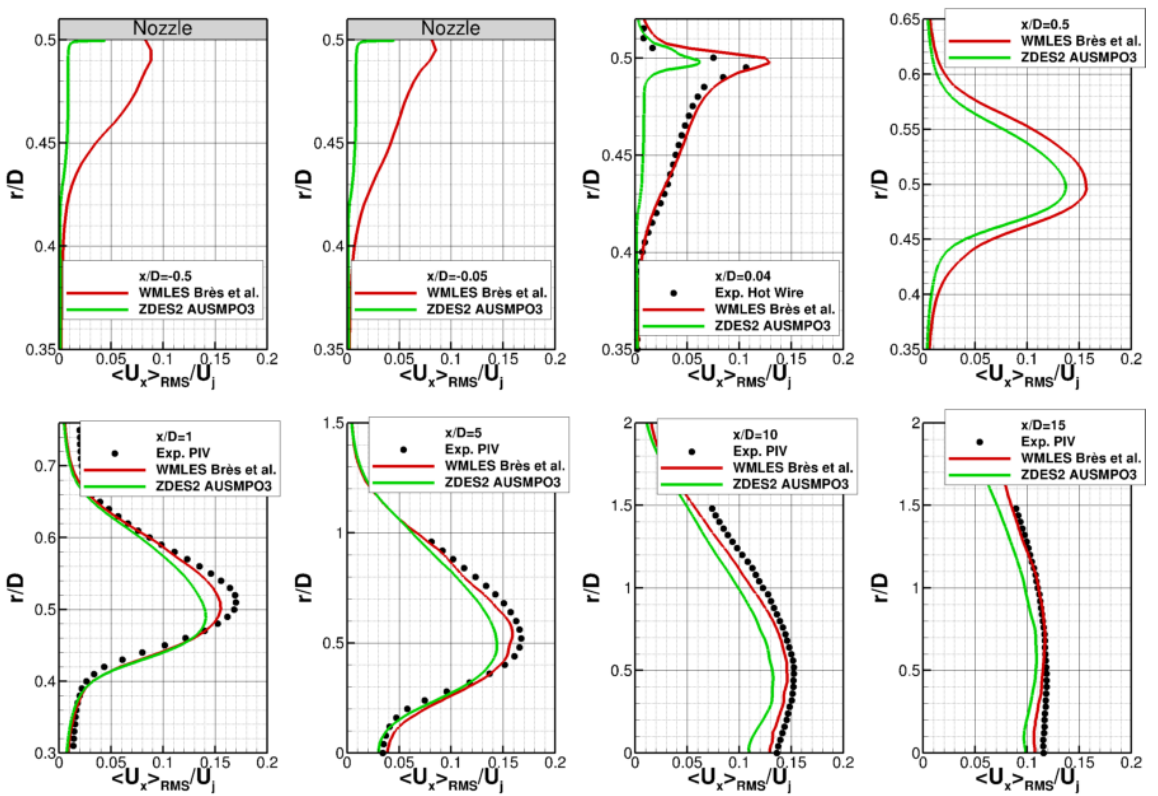

Figure 12. Shear layer RMS streamwise velocity profiles

\section{Spectral analysis}

Figure 13 presents the location of the numerical probes used to analyse the spectral distribution of the velocity and pressure fields in the shear layer and in the jet near-field.

In Figure 14, the velocity spectra along the shear layer for the ZDES mode 2 simulation further illustrate the RANS to LES process. In the final paper, the comparison with ZDES mode 3 will also to assess the efficiency of this approach in removing this pseudo laminar behaviour induced by a delay in the formation of the instabilities in the mixing layer.

Near field pressure spectra plotted in Figure 15 give some preliminary insights on the acoustics predicted by the ZDES mode 2 simulation. The results are in fair agreement with the database.

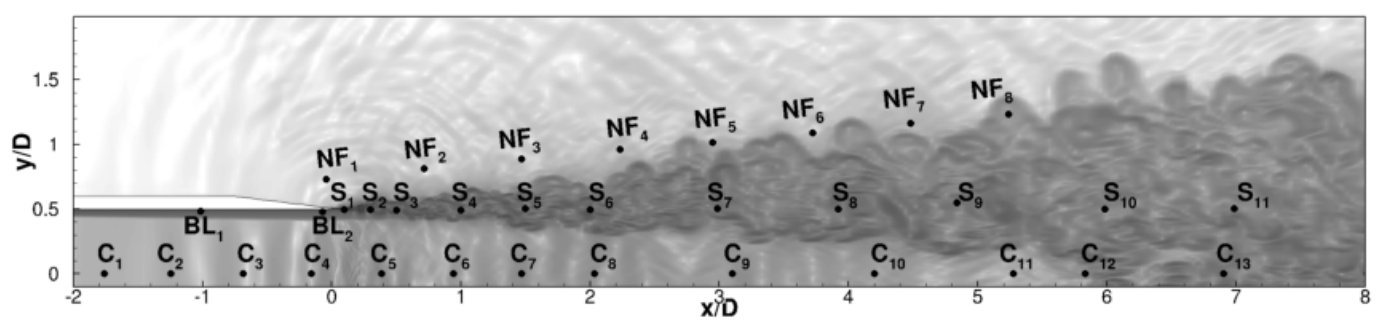

Figure 13. Location of the numerical sensors
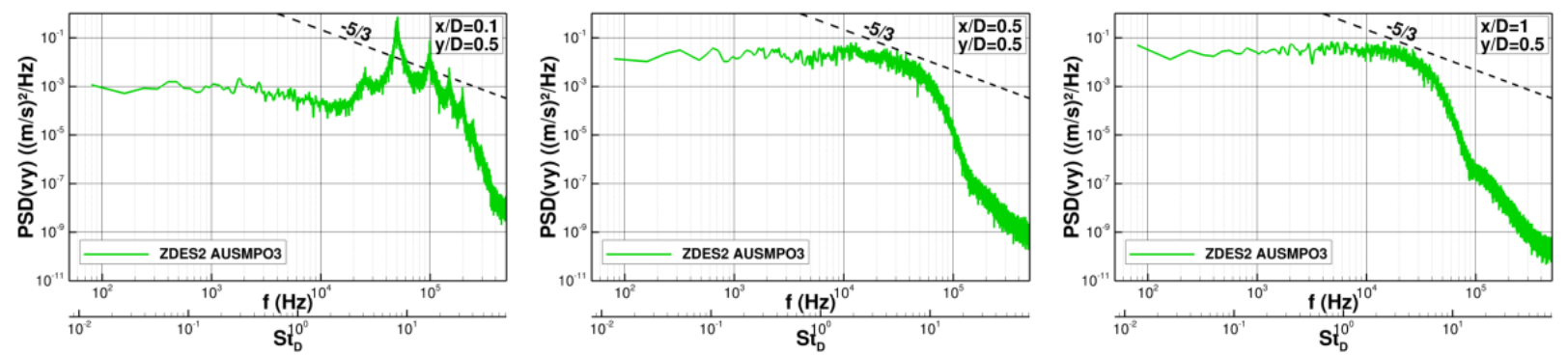

Figure 14. PSD of normal velocity (vy) in the shear layer (probes S1, S3, S4 and S9) 

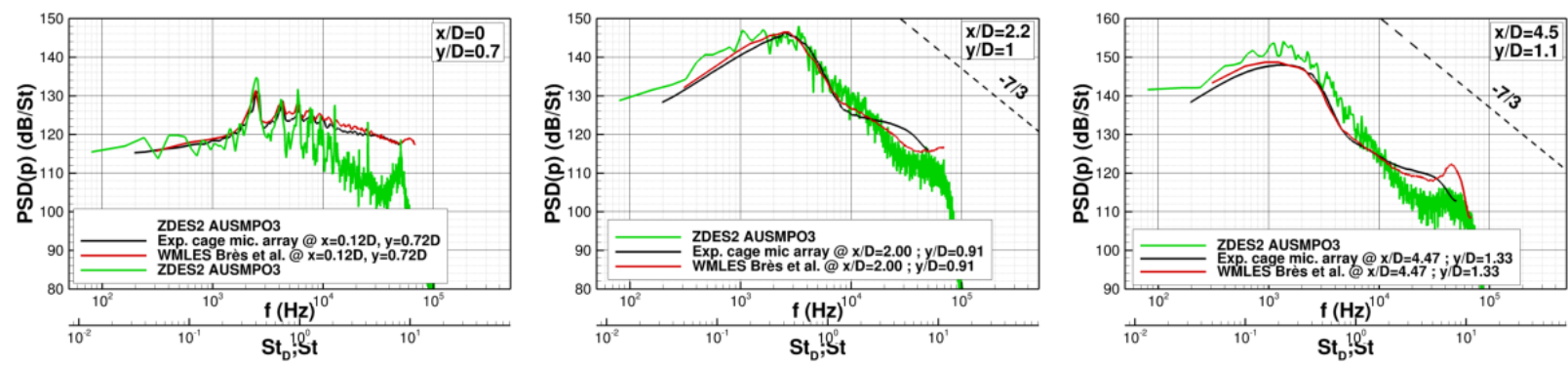

Figure 15. PSD of pressure in the jet near field (probes NF1, NF4 and NF8)

\section{Far-field acoustic results}

As mentioned in section IV, the FWH approach is used to compute the far-field radiated noise. Preliminary results are shown in Figure 16. The sound directivity is in fair agreement with the experimental data, but the sound levels are underestimated by 2 to $4 \mathrm{~dB}$. This is consistent with the velocity fluctuations presented in Figure 11 , and will be further analyzed in the final paper.

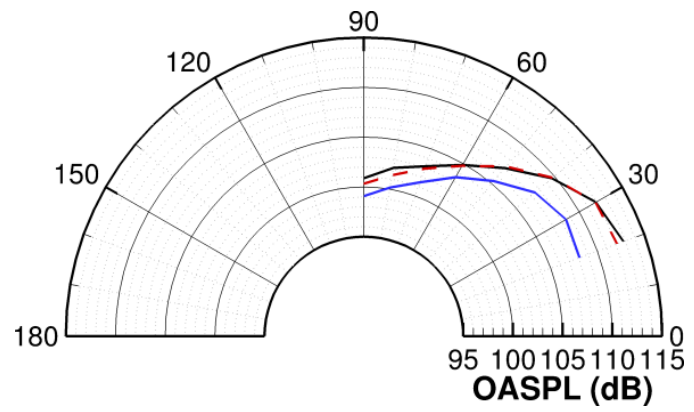

Figure 16. Overall sound pressure level directivity on the polar microphone array at 50D from the nozzle exit. - experiments ; - ZDES mode $2 ;--$ Brès et al. simulations [8]

\section{Conclusion}

In the final paper, the comparison of ZDES mode 2 and mode 3 simulations will allow assessing the improvement in the aerodynamic and aeroacoustic results obtained by using WMLES inside the nozzle. If so, some guidelines should be given to carry out similar simulations on different jet cases.

\section{Acknowledgements}

The Authors would like to thank G. Brès (Cascade Technolgies, Inc., Palo Alto, USA) and P. Jordan (Institut Pprime, Poitiers, France) for providing the experimental and numerical database before the online publication of this material.

\section{References}

[1] C. Bogey and O. Marsden, "Simulations of Initially Highly Disturbed Jets with Experiment-Like Exit Boundary Layers," AIAA Journal, pp. 1-14, Feb. 2016. doi: 10.2514/1.J054426.

[2] S. Deck, F. Gand, V. Brunet, and S. Ben Khelil, "High-fidelity simulations of unsteady civil aircraft aerodynamics: stakes and perspectives. Application of zonal detached eddy simulation," Philosophical 
Transactions of the Royal Society A, 2014. doi: 10.1098/rsta.2013.0325.

[3] S. Deck, "Recent Improvements of the Zonal Detached Eddy Simulation (ZDES) Formulation," Theoretical and Computational Fluid Dynamics, vol. 26, pp. 523-550, 2012. doi: 10.1007/s00162-011-0240-z.

[4] F. Gand, "Investigation of turbulence development in incompressible jets with zonal detached eddy simulation (ZDES) and synthetic turbulent inflow," International Journal of Heat and Fluid Flow, vol. Volume 61, Part B, pp. 425-437, 2016. doi: 10.1016/j.ijheatfluidflow.2016.06.003.

[5] F. Gand, M. Huet, T. Le Garrec, and F. Cléro, "Jet noise of a UHBR nozzle using ZDES: external boundary layer thickness and installation effects, " in AIAA Aeroacoustics Denver, CO., 2017.

[6] N. Renard and. S. Deck, "Improvements in Zonal Detached Eddy Simulation for Wall Modeled Large Eddy Simulation," AIAA Journal Technical Notes, 2015. doi: 10.2514/1.J054143.

[7] G. A. Brès et al., "Large eddy simulation for jet noise: the importance of getting the boundary layer right," in 21st AIAA/CEAS Aeroacoustics Conference, 26-26 june 2015, Dallas, TX. AIAA Paper 2015-2535, 2015.

[8] G. A. Brès et al., "Importance of the nozzle-exit boundary-layer state in subsonic turbulent jets," Journal of Fluid Mechanics, vol. 851, pp. 83-124, 2018. doi: 10.1017/jfm.2018.476.

[9] S. Deck, P.-E. Weiss, and N. Renard, "A rapid and low noise switch from RANS to WMLES on curvilinear grids with compressible flow solvers," Journal of Computational Physics, 2018. doi: 10.1016/j.jcp.2018.02.028.

[10] L. Cambier, S. Heib, and S. Plot, "The Onera elsA CFD software: input from research and feedback from industry," Mechanics and Industry, vol. 14, pp. 159-174, 2013. doi: 10.1051/meca/2013056.

[11] I. Mary and P. Sagaut, "Large Eddy Simulation of flow around an airfoil near stall," AIAA Journal, vol. 40 (6), pp. 1139-1145, 2002.

[12] J. E. Ffowcs Williams and D. L. Hawkings, "Sound generation by turbulence and surfaces in arbitrary motion," Philosophical Transactions for the Royal Society of London, vol. A264, pp. 321-342, 1969.

[13] G. Rahier, M. Huet, and J. Prieur, "Additional terms for the use of Ffowcs Williams and Hawkings surface integrals in turbulent flows," Computers and Fluids, vol. 120, pp. 158-172, 2015. 